Review

\title{
Curcumol: From Plant Roots to Cancer Roots
}

\author{
Wei Wei1 ${ }^{1}$ Azhar Rasul2,3, Ayesha Sadiqa ${ }^{3}$, Iqra Sarfraz ${ }^{3}$, Ghulam Hussain, Bushra Nageen³, Xintong Liu1, \\ Nobumoto Watanabe ${ }^{5}$, Zeliha Selamoglu' ${ }^{6}$, Muhammad Ali7, Xiaomeng $\mathrm{Li}^{2}{ }^{\circledR}$, Jiang $\mathrm{Li}^{1}{ }^{\circledR}$ \\ 1. Dental Hospital, Jilin University, Changchun 130021, China \\ 2. The Key Laboratory of Molecular Epigenetics of MOE, Institute of Genetics and Cytology, Northeast Normal University, Changchun 130024, China \\ 3. Department of Zoology, Faculty of Life Sciences, Government College University Faisalabad (GCUF), 38000, Pakistan \\ 4. Department of Physiology, Faculty of Life Sciences, Government College University Faisalabad (GCUF), 38000, Pakistan \\ 5. Bio-Active Compounds Discovery Research Unit, RIKEN Center for Sustainable Resource Science, Wako, Saitama 351-0198, Japan \\ 6. Department of Medical Biology, Faculty of Medicine, Nigde Ömer Halisdemir University, Nigde, Campus 51240 Turkey \\ 7. Quaid-e-Azam University, Islamabad, 45320, Pakistan
}

$\square$ Corresponding authors: Professor Jiang Li, Department of Prosthodontics, Dental Hospital, Jilin University, 1500 Tsinghua Road, Changchun, Jilin 130021, P.R. China. E-mail: ljiang@jlu.edu.cn; Tel: +86 186 86531019; Fax: +86 431-85579335; Professor Xiaomeng Li, The Key Laboratory of Molecular Epigenetics of Ministry of Education, Institute of Genetics and Cytology, Northeast Normal University, 5268 People's Street, Changchun, Jilin 130024, P.R. China. Email: lixm441@nenu.edu.cn; Tel: +86 13196048876; Fax: +86 431-85099285

(c) Ivyspring International Publisher. This is an open access article distributed under the terms of the Creative Commons Attribution (CC BY-NC) license (https://creativecommons.org/licenses/by-nc/4.0/). See http://ivyspring.com/terms for full terms and conditions.

Received: 2019.03.08; Accepted: 2019.05.02; Published: 2019.06.04

\begin{abstract}
Natural products, an infinite treasure of bioactive scaffolds, have provided an excellent reservoir for the discovery of drugs since millennium. These naturally occurring, biologically active and therapeutically effective chemical entities have emerged as novel paradigm for the prevention of various diseases. This review aims to give an update on the sources as well as pharmacological profile of curcumol, a pharmacologically active sesquiterpenoid, which is an imperative bioactive constituent of several plants mainly from genus Curcuma. Curcumol has potential to fight against cancer, oxidative stress, neurodegeneration, microbial infections, and inflammation. Curcumol has been documented as potent inducer of apoptosis in numerous cancer cells via targeting key signaling pathways as MAPK/ERK, PI3K/Akt and NF-KB which are generally deregulated in several cancers. The reported data reveals multitarget activity of curcumol in cancer treatment suggesting its importance as anticancer drug in future. It is speculated that curcumol may provide an excellent opportunity for the cure of cancer but further investigations on mechanism of its action and preclinical trials are still mandatory to further validate the potential of this natural cancer killer in anticancer therapies.
\end{abstract}

Key words: Anticancer, Biological activities, Curcumol, Natural products

\section{Introduction}

Natural products have been a magnificent and boundless source of vast chemical diversity driving pharmaceutical industry since times [1]. Medicinal plants are extensively utilized as herbal remedies for the prevention, cure, and treatment of wide spectrum of pathological conditions [2]. Modern drug discovery from natural products is a novel approach linking molecular, biological, phytochemical, and bioassay-guided fractionation techniques [3]. Plant products-based drug discovery yet remains an imperative domain where in depth research can definitely supply novel leads against numerous biological targets [4]. Many commercially accessible drugs have their origin from plants. Plant tissue culture approach has conventionally recognized as a potential alternate source for the production of some beneficial bioactive compounds [5].

The first written record on plants dates back to 2600 B.C. which is a refined medicinal scheme in Mesopotamia consisting of around 1000 drugs derived from medicinal plants [6]. Egyptian medicinal system, a data records from 2900 B.C., is composed of 700 drugs which are mainly originated from plants [7]. Over the past 50 decades, marine system has been an imperative source of about 20,000 noteworthy chemical entities. Of these, 9 are approved drugs 
while 12 are in clinical trials. All of these have been uncovered as molecules inspired from the natural products or their derivatives [8].

Numerous investigations on herbs and plants have assured their efficacy as compelling source of anticancer [3], antimicrobial [9], antiinflammatory [10], antioxidant [11], and neuroprotective agents [12, 13].

Sesquiterpenoids, saponins and diterpenoids have been abundantly found in medicinal plants, herbs and marine organisms. Due to broad range of diversity in their chemical structure, terpenes are well-known for their anticancer, antiinflammatory and neuroprotective potential in biological systems [14-18].

Till now, no one has attempted to review the anticancer activity of curcumol. Thus, this review aims to focus on the investigations associated with the pharmacological effectiveness of curcumol in various cancer types. The literatures were screened via many e-sites like PubMed, Elsevier Science Direct, Springer Link, and other related medical Journals. Keywords used for searching were "Natural products", "Curcumol", "Curcumol and its pharmacological potential", and "Anticancer".

\section{Curcumol and its natural sources}

Curcumol, a bioactive sesquiterpenoid, has been isolated from numerous plants of family Zingiberaceae. These plants are mostly found in
Southeast Asia, China, Indonesia, India, Peru, and West Indies [19]. Curcuma, the most important genus of the family Zingiberaceae, encompasses approximately 100 species. Curcumol has been isolated from $C$. longa which is an imperative species of the genus Curcuma and is generally known as common turmeric. Curcumol was also extracted from the rhizome of $C$. aeruginosae that is effective for antiinflammatory and antioxidant activities [20]. C. aromatic, a well-known natural source of curcumol, has been reported for its antitumor and antimicrobial activities [21]. C. kwangsiensis and C. phaeocaulis are advantageous for their antiproliferative activities against various cancer types [22-27]. Dried roots of $C$. zedoary enriched with curcumol are documented for their effective anticancer and antiinflammatory properties [28-31]. Rhizome of various Curcuma species, a rich source of curcumol, serves as antimicrobial, antifibrotic, and anticancer agent [32-34]. Besides them, curcumol has also been isolated from the roots of Astragali radix, C. rhizoma, and Fructus gardenia which are traditionally used as anticancer agents $[35,36]$.

The summary of plants containing curcumol and biological activities are enlisted in Table 1. Figure 1 provides natural sources of curcumol including Astragali radix [36], C. aeruginosae [20], C. aromatica [21], C. kwangsiensis [22], C. longa [37], C. phaeocaulis [24], C. wenyujin [38], C. zedoary [28], Fructus gardenia [35], and C. trichosantha G. [39].

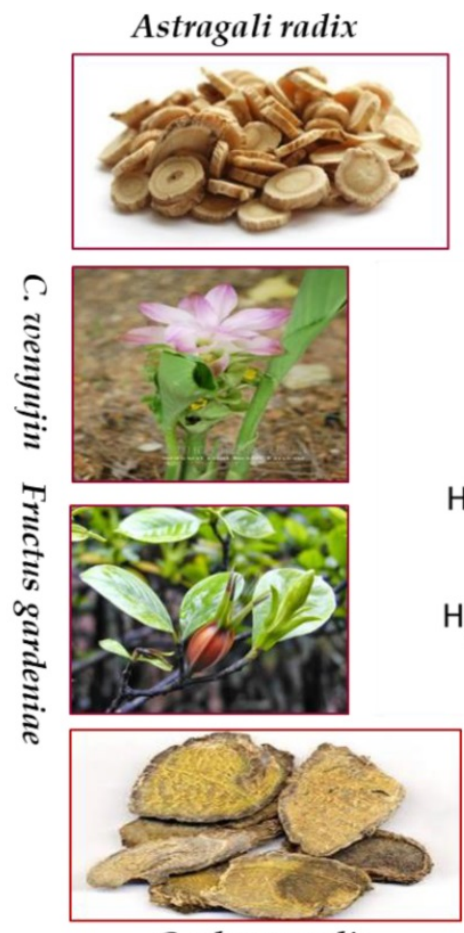

C. phaeocaulis
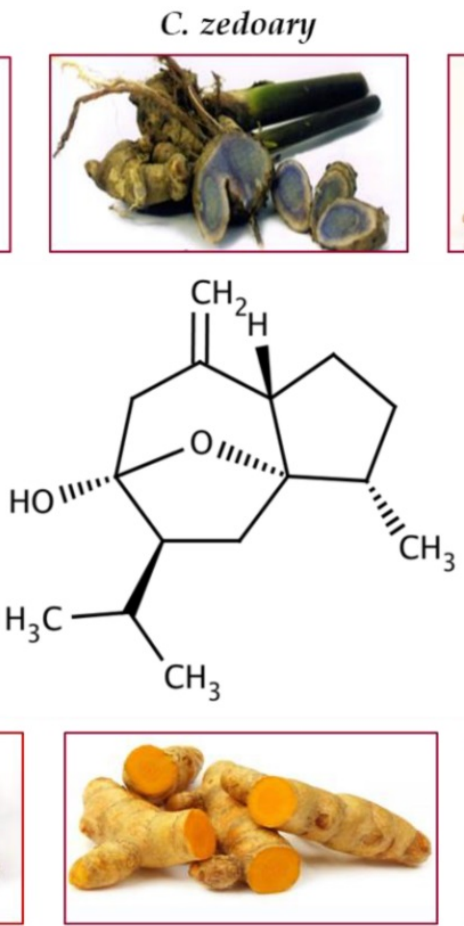

C. aromatica
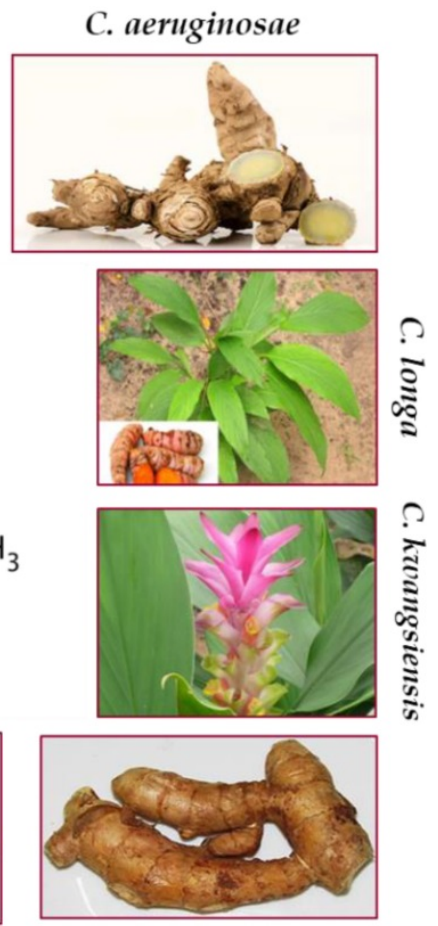

C. trichosantha

Figure 1. Chemical structure and natural sources of curcumol. 
Table 1. Natural sources of curcumol.

\begin{tabular}{llll}
\hline Name of Plants & \multicolumn{2}{l}{ Parts used/ Extract } & Disease/Function \\
\cline { 1 - 2 } Botanical Name & Common Name & & \\
\hline Astragali radix & Milkvetch root & Roots & Anticancer \\
Curcuma aeruginosae & Pink and blue ginger & Rhizome & Wound healing activity \\
Curcuma aromatica & Wild turmeric & Rhizome & \\
Curcuma kwangsiensis & --- & --- & Anticancer \\
Curcuma longa & Common turmeric & Rhizome & Antifungal \\
Curcuma phaeocaulis & --- & --- & Antiproliferative \\
Curcuma wenyujin & --- & --- & Antitumor, antihepatic fibrosis, antioxidant, antimicrobial \\
Curcuma zedoary & White turmeric & Dried roots & Anticancer \\
Fructus gardenia & --- & --- & Anticancer \\
Curcuma rhizoma & --- & --- & [22] \\
Curcuma trichosantha $\mathrm{G}$.-- & -- & Rhizome & [35] \\
\hline
\end{tabular}

\section{Biological activities of curcumol}

The pharmacologically active sesquiterpenoid, curcumol, is known to possess numerous pharmacological activities like anticancer, antimicrobial, antifungal, antiviral, and antiinflammatory. This chapter intends to focus on the mechanism by which curcumol acts on apoptosis related pathways to fight against cancer development and progression.

\subsection{Anticancer activities}

Cancer is a multifaceted disease characterized by genetic, epigenetic, signaling, and metabolic aberrations which contribute towards the deregulation of cellular homeostasis, growth, and apoptotic cell death [42]. Currently available cancer treatments such as chemotherapies and clinical drugs have limited success as they are correlated with various toxic effects and are also expensive. Therefore, this is an ultimate need of the time to find out reliable, inexpensive, and safe alternatives [3]. Naturally occurring bioactive molecules have been extensively investigated for their chemopreventive or chemotherapeutic potential due to biosafety, lesser toxicity, and availability as dietary supplements [43]. Cancer prevention by natural entities has emerged as a novel approach to combat the burden of cancer and this field of research is expanding day by day [44].

The significance of natural products can be estimated by the fact that $80 \%$ human population is still relying on plant-derived medications. Presently, greater than $60 \%$ of anticancer drugs represent their origin from natural products such as microorganisms, plants and marine flora [45]. Dietary utilization of vegetables and fruits are associated with reduction of cancer incidences by $20 \%$ and prevention of 200,000 cancer related mortalities annually [46]. In contrary to synthetic drugs which are monotargeted, these nature-derived molecules are multitarget in action having promising potential to halt cancer development and progression [47]. Presently, there is a growing trend towards screening of extracts from natural flora for drug discovery against cancer because of their capability to prohibit carcinogenesis via modulation of various cellular signaling pathways [48].

Secondary metabolites that are derived from plants like terpenes, polyphenols, and alkaloids have been reported for their potential anticancer efficacy $[49,50]$. Approximately, 55,000 terpenes have been identified from natural sources but only a limited number of entities have been screened for their anticancer potential [42]. Sesquiterpenoids, saponins, and diterpenoids as major classes of terpenes are widely known for their anticancer capabilities against broad range of cancers [15-17]. Sesquiterpenoids has been documented to act as anticancer, antiinflammatory, and neuroprotective agents in biological systems [18]. Curcumol is a guaiane type sesquiterpene lactone containing a vinylidene group along with hemiketal system [51]. Curcumol has been documented to owe potential anticancer activity against wide spectrum of cancers such as lung [52], breast [53], nasopharyngeal [54], gastric [23], liver [55], colorectal [56], and ovarian carcinoma's [57] (Figure 2).

\subsubsection{Curcumol and cell cycle arrest}

Since cancer represents a pathological condition with uncontrolled cellular division [58], therefore, naturally occurring bioactive entities regulating cell cycle or inhibiting mitotic divisions are affirmed to be promising candidates for chemotherapies [59, 60]. Investigations on cell cycle regulatory mechanisms have declared the fact that nature-derived chemotherapeutic entities are imperative for reinforcing the potency of targeted therapies [61]. Nature crafted molecules have pronounced ability to regulate the expression of cyclins, cyclin dependent kinases (CDKs) and various proteins and enzymatic machineries that are involved in cell cycle regulation. Naturally occurring bioactive entities regulating cell cycle or inhibiting mitotic divisions could be 
promising candidates for chemotherapies [61, 62].

Curcumol has been known to arrest the cell cycle at both G2/M and G0/G1 in several cancerous cells such as lung [52], breast [53], gastric [23], nasopharyngeal [63], and liver carcinomas [55]. In A549 and H1299 carcinoma cells, combinatorial treatment of celecoxib with curcumol lead to the accumulation of cells at G0/G1 phase while population of cells in $S$ phase was found to be dropped after the treatment. Thus, it is concluded that curcumol can reinforce the antiproliferative potential of celecoxib due to its capability of arresting cell cycle at G0/G1 phase [64]. ASTC-a-1cells treated with curcumol displayed nuclear shrinkage, membrane blebbing, membrane frilling along with G2/M cell cycle arrest [52]. SPC-A-1, TE-1, and AGS cells displayed substantial G0/G1 arrest while TE-1, AGS, and MGC-803 exhibited G2/M arrest followed by the treatment of curcumol [23, 32, 65]. Curcumol significantly prohibited growth of CNE-2 cells and caused cell cycle arresting at G0/G1 phase via increasing the expression of p21 and p27 while reducing the expression of CDKs and cyclins in a dose-dependent mode [63]. Curcumol treatment lead HepG2 cells towards G1 phase arrest mediated by mechanism activating $\mathrm{pRB}$ and $\mathrm{p} 53$ pathways which ultimately resulted in decreased cyclin A1 levels while enhanced mRNA expression level of p27KIP1, cyclin D1, CDK2, and CDK8 [55] (Table 2).

Table 2. Molecular targets of curcumol in different cancer types.

\begin{tabular}{|c|c|c|c|c|c|c|c|}
\hline \multirow[t]{2}{*}{ Type of cancer } & \multirow[t]{2}{*}{ Cell line } & \multicolumn{2}{|c|}{ Treatment conditions } & \multirow[t]{2}{*}{ IC $50 /$ Dose } & \multirow[t]{2}{*}{ Molecular targets } & \multirow{2}{*}{$\begin{array}{l}\text { Cell } \\
\text { cycle } \\
\text { arrest }\end{array}$} & \multirow[t]{2}{*}{ References } \\
\hline & & $\begin{array}{l}\text { No. of } \\
\text { cells/well }\end{array}$ & $\begin{array}{l}\text { Treatment } \\
\text { time }\end{array}$ & & & & \\
\hline \multirow[t]{3}{*}{ Lung } & A549, H1299 & $2 \times 10^{6}$ & $24 \mathrm{~h}$ & $30 \mu \mathrm{M}$ & 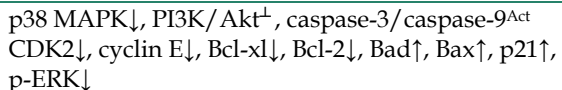 & G0/G1 & [64] \\
\hline & ASTC-a-1 & - & $3 \mathrm{~h}, 6 \mathrm{~h}, 12 \mathrm{~h}$ & $100 \mu \mathrm{M}$ & $\Delta \Psi \mathrm{m} \downarrow$ & $\mathrm{G} 2 / \mathrm{M}$ & [52] \\
\hline & SPC-A-1 & $2 \times 10^{6}$ cells & $72 \mathrm{~h}$ & $32.7 \mu \mathrm{M}$ & - & G0/G1 & [32] \\
\hline \multirow[t]{4}{*}{ Nasopharyngeal } & CNE-2 & $2 \times 10^{3}$ & $24 \mathrm{~h}, 72 \mathrm{~h}$ & - & $\begin{array}{l}\mathrm{NCL}^{\perp} \\
\text { (Nucleolin) }\end{array}$ & - & [28] \\
\hline & CNE-2 & - & - & - & $\mathrm{NF}-\mathrm{kB} \downarrow$ & - & [54] \\
\hline & NPC $5-8 \mathrm{~F}$ & $5 \times 10^{5}$ & $48 \mathrm{~h}$ & $\begin{array}{l}0,0.1,0.2,0.4 \\
\mu \mathrm{M} / \mathrm{ml}\end{array}$ & $\mathrm{N}$-cadherin $\perp$, E-cadherin $\uparrow$ & - & [66] \\
\hline & CNE-2 & $3 \times 10^{3}$ per well & $24,48,72,96 \mathrm{~h}$ & $50 \mu \mathrm{g} / \mathrm{ml}$ & 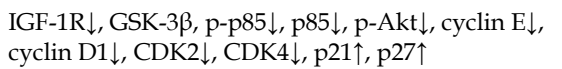 & G0/G1 & [63] \\
\hline \multirow[t]{4}{*}{ Breast } & MDA-MB-231 & $4 \times 10^{3}$ & $48 \mathrm{~h}, 72 \mathrm{~h}$ & $\begin{array}{l}85.0 \mu \mathrm{g} / \mathrm{ml}, 13.5 \\
\mu \mathrm{g} / \mathrm{ml}\end{array}$ & $\begin{array}{l}\mathrm{p} 73 \uparrow, \mathrm{Bak} \uparrow \\
\mathrm{PUMA} \uparrow\end{array}$ & G1 & [38] \\
\hline & $\begin{array}{l}\text { MDA-MB-231, } \\
4 \mathrm{~T} 1\end{array}$ & $0.8 \times 10^{4}$ & $24 \mathrm{~h}$ & - & MMP-9 $\downarrow$, p-JNK $1 / 2 \perp$, p-Akt ${ }^{\perp}$, NF-kB ${ }^{\perp}$ & - & [53] \\
\hline & MDA-MB-231 & $1 \times 10^{5}$ & $24 \mathrm{~h}$ & $20 \mu \mathrm{g} / \mathrm{ml}$ & eEF1A1 & - & [67] \\
\hline & $\begin{array}{l}\text { AGS, } \\
\text { MGC- } 803\end{array}$ & $\begin{array}{l}1.0 \times 10^{4} \\
\text { cells } / \mathrm{ml}\end{array}$ & $24,48,72 \mathrm{~h}$ & $\begin{array}{l}72.40,64.28 \\
63.83 \mu \mathrm{g} / \mathrm{ml}\end{array}$ & 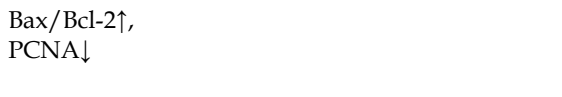 & $\begin{array}{l}\mathrm{S}, \\
\mathrm{G} 2 / \mathrm{M}, \\
\mathrm{G} 0 / \mathrm{G} 1\end{array}$ & [23] \\
\hline Gastric & MGC-803 & - & $24,48,72 \mathrm{~h}$ & - & $\mathrm{MMP} \downarrow, \mathrm{IDH} 1 \downarrow, \mathrm{ROS} \uparrow$ & $\mathrm{G} 2 / \mathrm{M}$ & [68] \\
\hline \multirow[t]{2}{*}{ Liver } & HSC-T6 & - & $48 \mathrm{~h}$ & $300 \mu \mathrm{M}$ & $\begin{array}{l}\text { PARP cleavage, caspase-3Act, NF-кB translocation } \downarrow \text {, } \\
\text { p-IкB- } \alpha^{\perp}, B c 1-2 \downarrow, \text { Bcl-xl } \downarrow\end{array}$ & - & [27] \\
\hline & HepG2 & - & - & - & 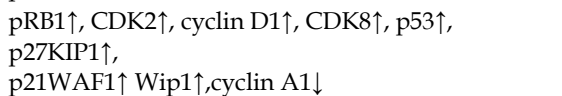 & G1 & [55] \\
\hline \multirow[t]{4}{*}{ Colorectal } & LoVo & $8 \times 10^{2}$ & $\begin{array}{l}24,48,72,96 \\
\text { and } 120 \mathrm{~h}\end{array}$ & $\begin{array}{l}0.48,0.31,0.24 \\
0.15,0.11 \mu \mathrm{M}\end{array}$ & 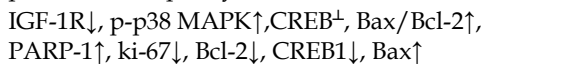 & 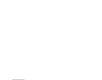 & [56] \\
\hline & LoVo & $1 \times 10^{4}$ & $\begin{array}{l}24,48,72,96, \\
\text { and } 120 \mathrm{~h}\end{array}$ & $93.59 \mu \mathrm{g} / \mathrm{ml}$ & NF-kB $\downarrow$, PTEN $\uparrow, ~ p-p 85 \downarrow$, p $85 \downarrow$, p-Akt $\downarrow$, Akt $\downarrow$ & - & [69] \\
\hline & HCT-116 & $1 \times 10^{4}$ & $\begin{array}{l}24,48,72,96 \\
\text { and } 120 \mathrm{~h}\end{array}$ & $76.15 \mu \mathrm{g} / \mathrm{ml}$ & $\operatorname{miR}-21 \downarrow$ & - & [69] \\
\hline & SW480 & $1 \times 10^{4}$ & $\begin{array}{l}24,48,72,96 \\
\text { and } 120 \mathrm{~h}\end{array}$ & $209.09 \mu \mathrm{g} / \mathrm{ml}$ & - & - & [69] \\
\hline Choriocarcinoma & JEG-3 & - & - & $75 \mu \mathrm{g} / \mathrm{ml}$ & DNMT1 $\downarrow$, DNMT3b $\downarrow, H D A C 1 \downarrow, H D A C 3 \downarrow$ & - & [29] \\
\hline Osteosarcoma & MG-63 & $\begin{array}{l}1 \times 10^{4} \\
\text { cells/well }\end{array}$ & $48 \mathrm{~h}$ & $63.5 \mathrm{mg} / 1$ & $\mathrm{p}-\mathrm{JNK} \uparrow$ & - & [70] \\
\hline Ovarian & SKOV3 & - & - & - & JAK $2 \perp$, STAT- $3 \perp$ & - & [57] \\
\hline \multirow[t]{2}{*}{ Bladder } & EJ & $5 \times 10^{3}$ & $24,48,72 \mathrm{~h}$ & $\begin{array}{l}12.5,25,50,100 \\
\mathrm{mg} / \mathrm{ml}\end{array}$ & $\mathrm{EZH} 2 \downarrow$ & - & [71] \\
\hline & $\mathrm{T} 24$ & $5 \times 10^{3}$ & $24,48,72 \mathrm{~h}$ & $\begin{array}{l}12.5,25,50,100 \\
\mathrm{mg} / \mathrm{ml}\end{array}$ & $\mathrm{EZH} 2 \downarrow$ & - & [71] \\
\hline
\end{tabular}




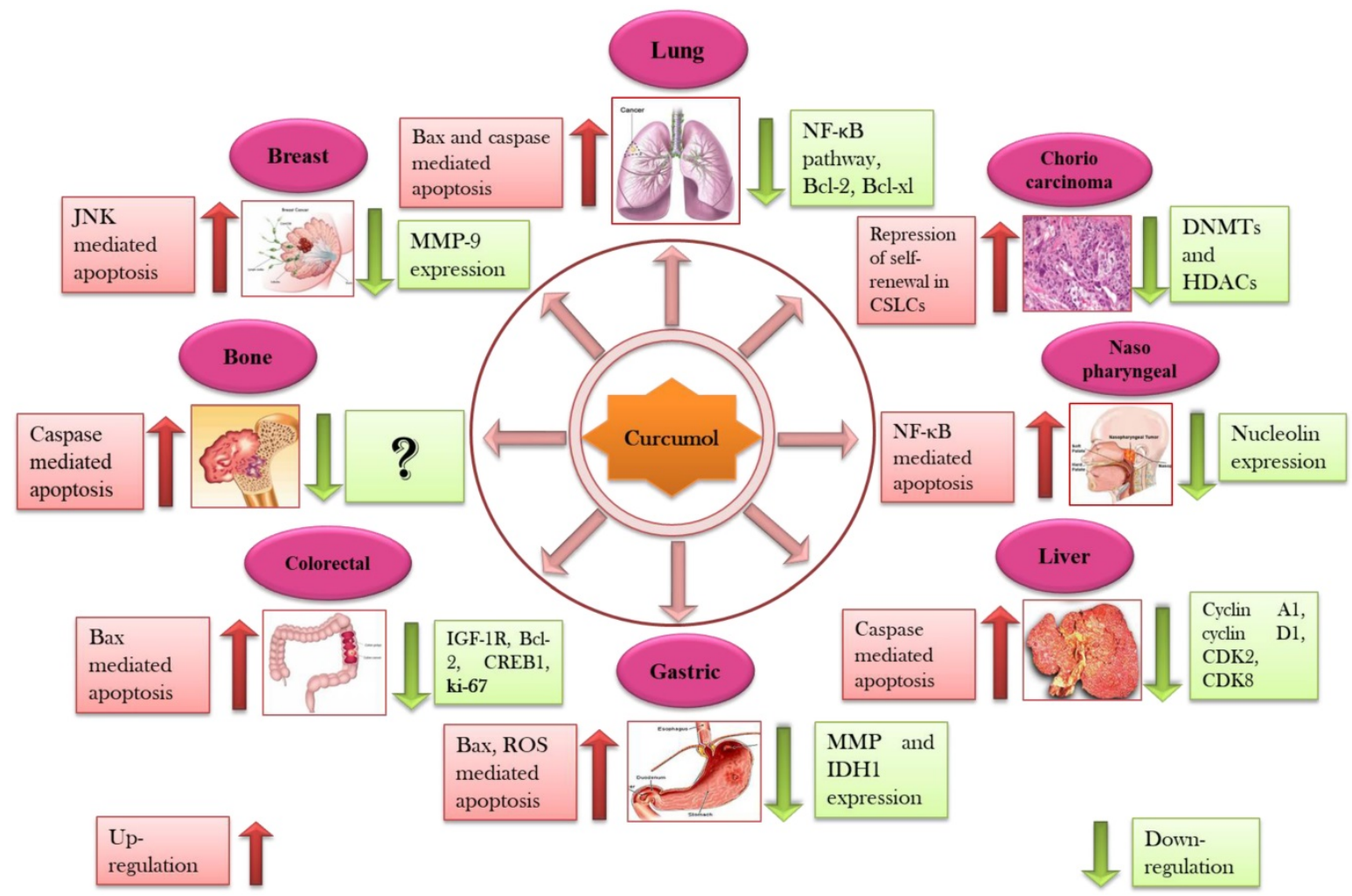

Figure 2. Cytotoxic effects of curcumol against numerous types of cancer through interruption with various cell signaling pathways (Details of different types of cancer with their molecular targets are presented in Table 2).

It can be contemplated that curcumol halt the cell cycle at G0/G1 or G2/M phase but the question that whether in G2, M, G1 or G0 phase still demands further investigation. While cyclin B and E also play crucial role in cell cycle progression, thus, further studies should also explore the role of curcumol on these cyclins. Thus, future studies are clearly needed to understand the mechanism through which curcumol cause cell cycle arrest in various cancer types.

\subsubsection{Curcumol and apoptosis}

Apoptosis is a synchronized form of cellular death in which various intracellular events function together to get rid of unwanted or harmful cells from human body [72]. Apoptotic cell death is considered as an important characteristic of biological events such as embryonic development, normal cellular turnover, and functioning of immune system [73]. Irregular or improper apoptosis provides a platform for the development of diseased conditions such as autoimmune responses, ischemic damage, neurodegenerative disorders, and cancer [74-76]. Intrinsic/extrinsic apoptotic pathways control apoptosis via activation of intracellular machineries of death proteases known as caspases. These activated caspases are imperative prosecutioners of programmed cell death [77]. Multiple lines of evidences have declared the fact that naturally occurring chemopreventive agents have potential to induce apoptosis in tumor cells via modulation of various molecular machineries in intrinsic and extrinsic apoptotic pathways [78-83].

Curcumol has been turned up as unique paradigm for the multitargeted prevention of cancer. Anticancer potential of curcumol has been declared to be linked with apoptosis induction via p53 regulation [55], accumulation of ROS/oxidative stress [68], reducing antiapoptotic proteins (Bcl-2, Bcl-xl) [27, 64], increasing proapoptotic proteins (Bax, Bad) [64], modulation of MAPK pathway (inhibition of p-JNK1/2, upregulation of p-p38 MAPK) [56, 64], inhibition of NF-kB [64], triggering PARP cleavage [27], activation of caspase cascade, and diminishing mitochondrial membrane potential [52] (Figure 3).

\subsubsection{Curcumol and NF-KB pathway}

NF-KB represents the superfamily of transcriptional factors that regulates the expression of various genes associated with survival, development, angiogenesis, proliferation, invasion, and metastasis [84]. This intracellular signaling cascade has potential to induce structural modification in chromatin to mediate transcription, cell cycle control, apoptosis, and cellular transformations [85]. Thus, targeting $\mathrm{NF}-\mathrm{kB}$ and its regulated gene expressions offer a 
promising strategy for cancer therapy [86].

Plant-derived chemical entities have been documented to induce cellular apoptosis via targeting multi-functional transcription domain NF-kB [87]. Combined treatment of celecoxib with curcumol in A549 and H1299 cancerous cells leads to the prohibition of nuclear translocation of p65 while upregulated the IкBa levels [64]. Curcumol has potential to stimulate apoptosis in CNE-2 cells via down modulation of NF-KB activity [54]. Curcumol decreased the invasive ability of MDA-MB-231 cells via prohibition of MMP-9 and suppression of Akt and JNK1/2-dependant NF-kB activity [53]. In HSC-T6 cells, curcumol effectively downregulated the nuclear translocation of NF- $\mathrm{kB}$ through inhibiting p-ІкB-a which leads towards modulation of NF-kB associated gene expressions such as Bcl-xl and Bcl-2 [27]. Although it has been declared that curcumol induce apoptosis via NF-kB inhibition but whether it directly targets NF-kB or via its upstream pathways such as JAK or STAT-3 should be explored.

\subsubsection{Curcumol and MAPK and PI3K/Akt pathway}

MAPK pathway encompasses key signaling kinases and phosphorylation events which perform a crucial role in carcinogenesis [88]. Three subgroups of MAPK pathway: JNKs, ERKs, and p38 MAPKs carry extracellular signals which regulate cellular differentiation, apoptosis, proliferation, and invasion $[88,89]$. The PI3K/Akt pathway as a regulator of multiple cellular events also plays a significant role in development of tumors and their progression [90]. Thus, MAPK and PI3K/Akt associated signaling pathways epitomize a novel target for cancer therapies.

Combined treatment of celecoxib with curcumol in A549 and H1299 cells decreased the phosphorylation level of PI3K, Akt, ERK, and p38 MAPK which accounts for the apoptotic effect of given treatment. As it is well established fact that deregulated mitogenic and PI3K pathways with their downstream pathway NF-kB have capability to inhibit apoptosis and to intensify cellular proliferation [64]. Curcumol treatment induced apoptosis in LoVo cells via phosphorylation of p38 MAPK [56]. Curcumol suppresses JNK1/2 and Akt activation because it has potential to inhibit p-JNK1/2 and p-Akt in MDA-MB-231 cells [53]. Curcumol has potential to downregulate the proliferation of colorectal cancerous cells by modulating PTEN/PI3K/Akt pathways [69]. Although it has been documented that curcumol inhibited the phosphorylation of Akt at Ser- 473 but whether it can inhibit the Akt phosphorylation at Thr-308 site or not still need to be investigated.

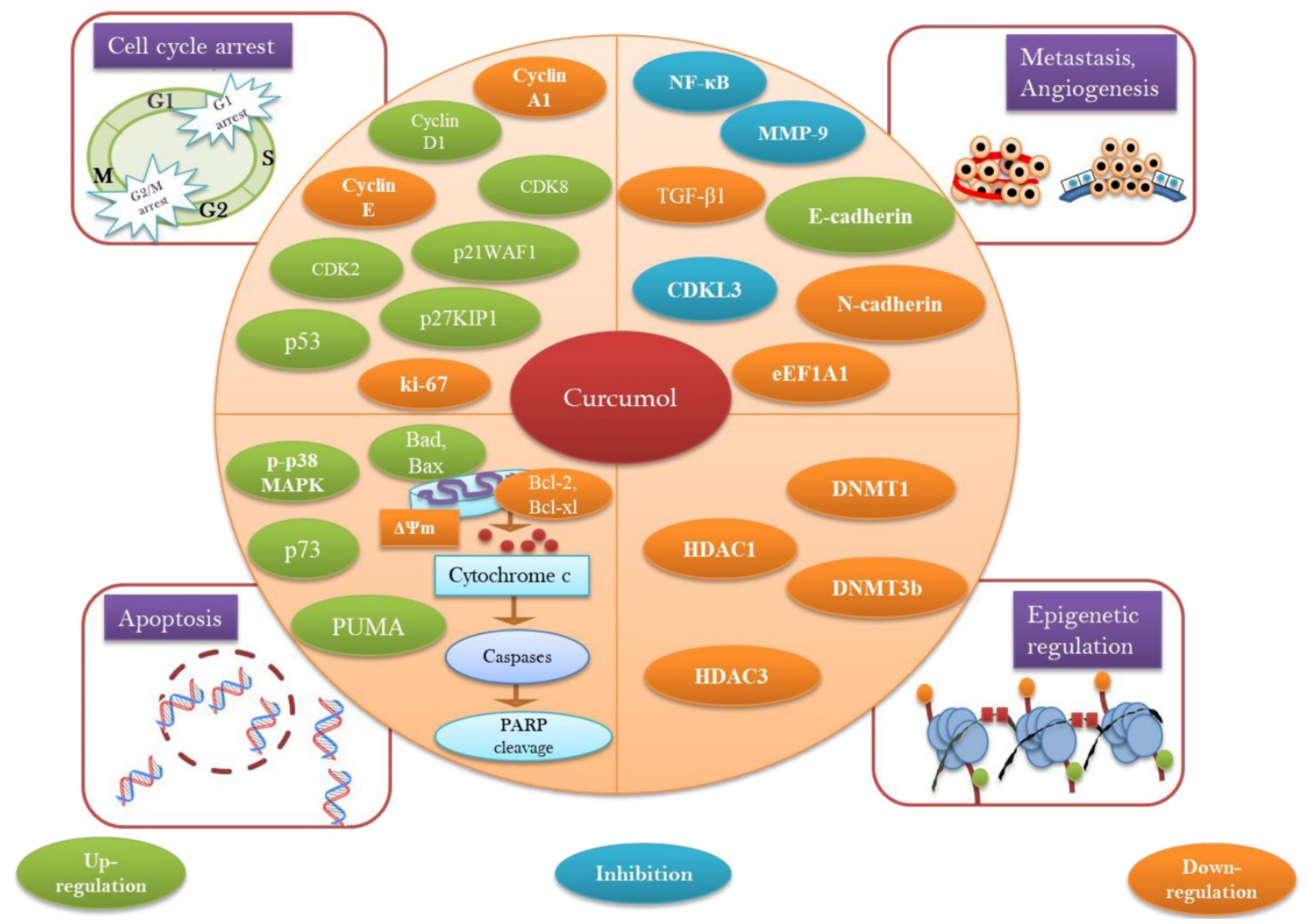

Figure 3. A diagrammatic representation of molecular targets and mechanism of action for anticancer activity of curcumol. 


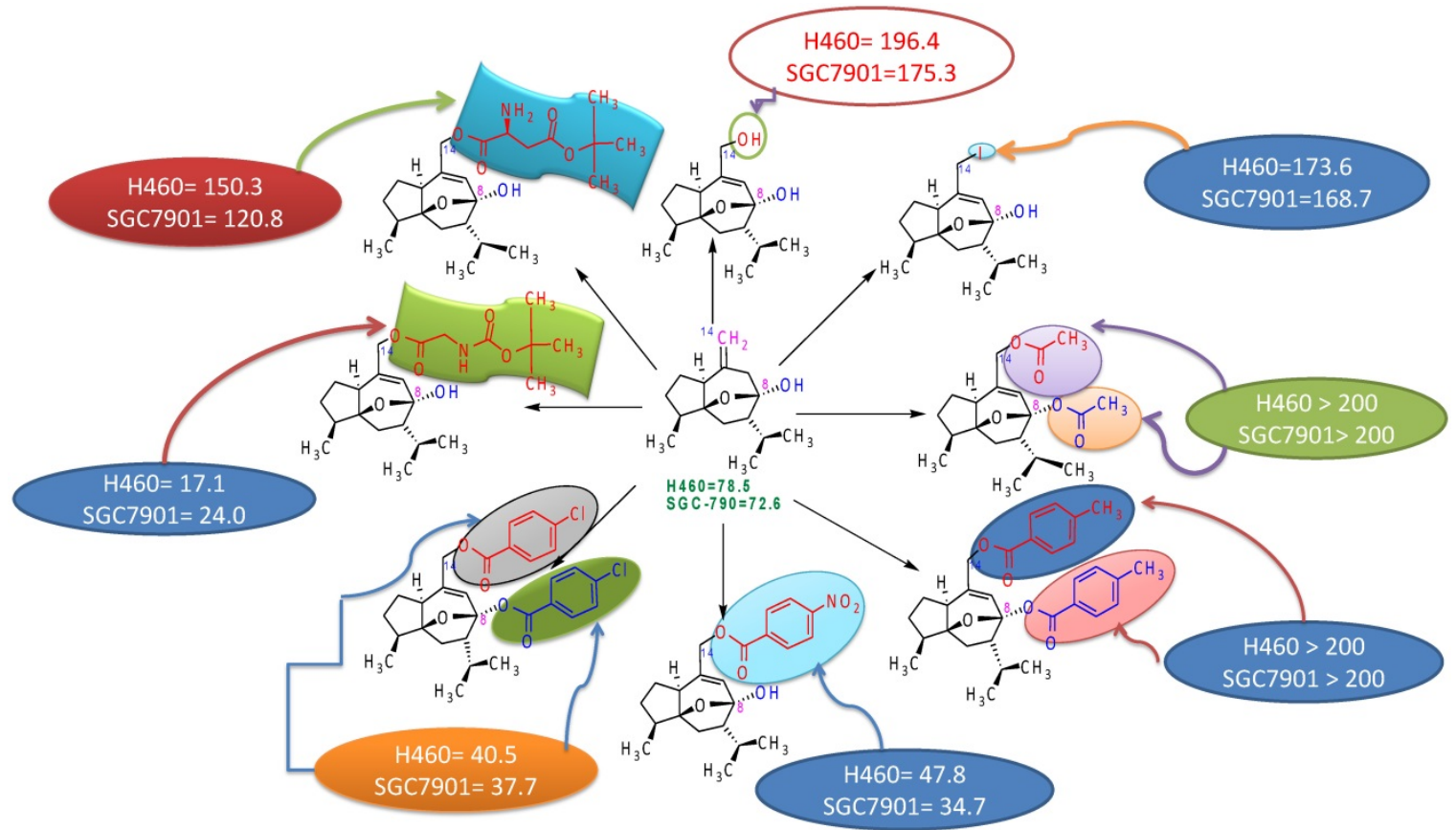

Figure 4. Structure activity relationship of curcumol.

\section{In vivo studies and biosafety profiles}

Curcumol has also been studied in vivo in CSLCs (cancer stem like cells) tumor-bearing mouse model induced by subcutaneous inoculation of JEG-3 cells into the left flank of mouse. Oral administration of 200 $\mathrm{mg} / \mathrm{kg}$ curcumol on daily basis for 10 days resulted in significant shrinkage in both tumor volume and weight. More interestingly, curcumol treated mouse survived longer as compared to DMSO/control group. Thus, curcumol has the potential to inhibit the stemness capability of choriocarcinoma CSLCs [29]. In another study, curcumol was investigated in xenograft tumor mouse model in which cancer was induced by subcutaneous injections of NPC 5-8F cells. Administration of curcumol at the concentration of 15 $\mu \mathrm{g} / \mathrm{kg}$ crude drug by gavage two times a day for 35 days significantly inhibited tumor growth. Curcumol treated group also showed reduced expression of TGF- $\beta 1$ and N-cadherin while increased expression of E-cadherin resulting in blockage of epithelialmesenchymal transition [66]. LoVo cells xenografted mouse model showed $70 \%$ inhibition of tumor without any loss in body weight when curcumol was administered at the dose of $80 \mathrm{mg} / \mathrm{kg}$ [56]. Combined treatment of celecoxib and curcumol for 6 days inhibited the tumor metastasis and invasion in mouse model xenografted by tail vein injection of A549 cells into nude mouse. Furthermore, researchers have clearly declared that administration of curcumol alone or in combination with celecoxib induced no distinct toxicity and no alterations in body or liver weight [64].
However, to access the biosafety profiles of curcumol, investigations affiliated with the identification of nephrotoxicity, genotoxicity and reproductive toxicity should be conducted in the future. Moreover, it is also suggested that multitudinal in vivo studies should be executed in future to assess the efficacy of curcumol as chemotherapeutic agent in combinatorial therapies.

\section{Structure activity relationship}

Studies to discover the structure-activity relationship of curcumol revealed that position- 8 and position-14 are very important in improving the antitumor activity of curcumol. Electron-withdrawing groups increase the antitumor activity of curcumol as observed by comparing the activities of different derivatives of curcumol (Figure 4) [91, 92]. Presence of free hydroxyl at position- 8 is responsible for increased antitumor activity but if this hydroxyl has esterified; then it led to significant decrease in antitumor activity. For example, 14-hydroxy curcumol (derivative 1) showed 196.4 activity against lung carcinoma cell line $\mathrm{H} 460$ and 175.3 against gastric cancer cell line SGC-790 due to presence of free hydroxyl at position-14 in place of double bond $(=)$ in comparison to curcumol which showed activity 78.5 against lung carcinoma cell line $\mathrm{H} 460$ and 72.6 against gastric cancer cell line SGC-790. This comparison showed a much enhanced increment in activity by substitution of double bond with hydroxyl group. Similarly, comparison of derivative 1 with 14-iodocurcumol revealed that the substitution of hydroxyl group at position-14 by iodine led to a 
decrease in antitumor activity (Figure 4).

Thus, it has been concluded that the structure-activity relationship of curcumol depends upon substituents present at position- 8 and 14 . The enhanced antitumor activity of curcumol is due to the presence of free hydroxyl \& cyclic structure. The substitution of double bond by electron withdrawing group also led to an enhanced increment in antitumor activity [91].

\section{Conclusions and future recommendations}

In this article, we have focused on the progress of curcumol as anticancer agent. Collectively, data from various investigations have provided imperative clues for key role of curcumol in treatment of cancer. Curcumol exhibits wide range of toxicity against numerous cancer cell lines. This anticancer sesquiterpenoid fights against cancer development and progression by cell cycle arrest, apoptosis induction, and regulation of various signaling cascades followed by modulation of cell cycle mediators, apoptosis related proteins, transcriptional factors, protein kinases, cytokines, and growth receptors. After the critical evaluation of reported data, we found that curcumol shows most potent anticancer activity against LoVo cancerous cells with $\mathrm{IC}_{50}$ of $0.11 \mu \mathrm{M}$. Thus, it is strongly recommended to conduct further mechanistic studies because colorectal cancer is the $3^{\text {rd }}$ most reported cancer of men and the $2^{\text {nd }}$ in women around the world. Curcumol might serve as an attractive candidate as it has the capability to repress self-renewal of cancer stem cells. Thus, further investigations should be conducted in order to explore its potential against cancer stem cells (CSCs) because CSCs have novel therapeutic opportunity to combat with deadly diseases like cancer. As curcumol has been isolated from various traditional Chinese medicines and being an important constituent of turmeric which is a principal spice in Southeast Asia, it might turns up as safe chemotherapeutic agent in future. Moreover, curcumol possesses in vitro efficacy and selectivity suggesting that further in vivo studies, preclinical and clinical analysis should be conducted to assure the potential of curcumol for therapeutic indication. It is anticipated that assembled information will pave a new path for research community towards authentication and establishment of this natural cancer killer as a felicitous pharmacological drug in the near future.

\section{Abbreviations}

$\uparrow$ : Upregulation; $\downarrow$ : Downregulation; $\perp$ : Inhibition; Act: Activation; Bax: Bcl-2-associated $\mathrm{x}$ protein; Bcl-2: B-cell lymphoma 2; JNK: c-Jun N-terminal kinase; JAK2: Janus kinase 2; NF-KB: Nuclear factor kappa-light-chain-enhancer of activated B cells; MAPK: Mitogen-activated protein kinase; TNF-a: Tumor necrosis factor-a; ROS: Reactive oxygen species; CDK2: Cyclin-dependent kinase 2; Chk2: Checkpoint kinase 2; STAT-3: Signal transducer and activator of transcription 3; CDK8: Cyclin-dependent kinase 8; Cip1/p21: Cyclindependent kinase inhibitor p21; ERK: Extracellular signal-regulated kinase; MMP: Metalloproteinase; PI3K: Phosphatidylinositol-3-kinase; PCNA: Proliferating cell nuclear antigen (PCNA); IGF-1: Insulin-like growth factor 1; PARP1: Poly (ADP-ribose) polymerase; PUMA: p53 upregulated modulator of apoptosis (PUMA).

\section{Acknowledgments}

This study was supported by the Ministry of Science and Technology, China (No. 2016YFE0128500), Jilin Provincial Science and Technology Department (20170204009YY, 20180414057GH), Changchun Science \& Technology Department, China (17YJ001; 17YJ006); Jilin Province Development and Reform Commission(2016C048-3; 2016C047-3), National Natural Science Foundation of China (No. 31870758), University S \& T Innovation Platform of Jilin Province for Economic Fungi (\#2014B-1), the Program for Introducing Talents to Universities (No. B07017), The Nagai Foundation Tokyo, Japan (NFT-R4-2017; NFT-R-2018), TWASCOMSTECH Research Grant (No._17-180 RG/PHA/ AS_C) and NRPU Research Grants (8381/Punjab/ NRPU/R\&D/HEC/2017, 8382/Punjab/NRPU/ R\&D/HEC/2017). We would also like to thank Higher Education Commission (HEC), Pakistan for providing access to related papers from various journals.

\section{Competing Interests}

The authors have declared that no competing interest exists.

\section{References}

1. Mishra BB, Tiwari VK. Natural products: an evolving role in future drug discovery. European journal of medicinal chemistry. 2011; 46: 4769-807.

2. Hong J. Role of natural product diversity in chemical biology. Current opinion in chemical biology. 2011; 15: 350-4

3. Sarfraz I, Rasul A, Jabeen F, Younis T, Zahoor MK, Arshad M, et al. Fraxinus: A Plant with Versatile Pharmacological and Biological Activities. Evidence-based complementary and alternative medicine : eCAM. 2017; 2017: 4269868.

4. Sen T, Samanta SK. Medicinal plants, human health and biodiversity: a broad review. Advances in biochemical engineering/biotechnology. 2015; 147: 59-110.

5. Pant B. Application of plant cell and tissue culture for the production of phytochemicals in medicinal plants. Advances in experimental medicine and biology. 2014; 808: 25-39.

6. Atanasov AG, Waltenberger B, Pferschy-Wenzig EM, Linder T, Wawrosch C, Uhrin $\mathrm{P}$, et al. Discovery and resupply of pharmacologically active 
plant-derived natural products: A review. Biotechnology advances. 2015; 33: 1582-614

7. Cragg GM, Newman DJ. Natural products: a continuing source of novel drug leads. Biochimica et biophysica acta. 2013; 1830: 3670-95.

8. Gerwick WH, Fenner AM. Drug discovery from marine microbes. Microbial ecology. 2013; 65: 800-6.

9. Denev P, Kratchanova M, Ciz M, Lojek A, Vasicek O, Blazheva D, et al. Antioxidant, antimicrobial and neutrophil-modulating activities of herb extracts. Acta biochimica Polonica. 2014; 61: 359-67.

10. Riaz A, Rasul A, Hussain G, Zahoor MK, Jabeen F, Subhani Z, et al. Astragalin: A Bioactive Phytochemical with Potential Therapeutic Activities. Advances in pharmacological sciences. 2018; 2018: 9794625.

11. Kowalska T, Ciesla L. Assessment of Antioxidant and Antibacterial Potential of Medicinal Herbs and Botanical Preparations. Journal of AOAC International. 2015; 98: 847-9.

12. Hussain G, Rasul A, Anwar H, Aziz N, Razzaq A, Wei W, et al. Role of Plant Derived Alkaloids and Their Mechanism in Neurodegenerative Disorders. International journal of biological sciences. 2018; 14: 341-57.

13. Hussain G, Zhang L, Rasul A, Anwar H, Sohail MU, Razzaq A, et al. Role of Plant-Derived Flavonoids and Their Mechanism in Attenuation of Alzheimer's and Parkinson's Diseases: An Update of Recent Data. Molecules. 2018; 23.

14. Yang Y, Laval S, Yu B. Chemical synthesis of saponins. Advances in carbohydrate chemistry and biochemistry. 2014; 71: 137-226

15. Gach K, Dlugosz A, Janecka A. The role of oxidative stress in anticancer activity of sesquiterpene lactones. Naunyn-Schmiedeberg's archives of pharmacology. 2015; 388: 477-86.

16. Tian X, Tang H, Lin H, Cheng G, Wang S, Zhang X. Saponins: the potential chemotherapeutic agents in pursuing new anti-glioblastoma drugs. Mini reviews in medicinal chemistry. 2013; 13: 1709-24.

17. Sarkar S, Gopal PK, Paul S. Diterpenoids- potential chemopreventive and chemotherapeutic agents in leukemia. Current pharmaceutical biotechnology. 2014; 15: 127-42

18. Chadwick M, Trewin H, Gawthrop F, Wagstaff C. Sesquiterpenoids lactones: benefits to plants and people. International journal of molecular sciences. 2013; 14: 12780-805.

19. Sun W, Wang S, Zhao W, Wu C, Guo S, Gao H, et al. Chemical constituents and biological research on plants in the genus Curcuma. Critical reviews in food science and nutrition. 2017; 57: 1451-523.

20. Zhou J, Ni M, Liu X, Ren Z, Zheng Z. Curcumol Promotes Vascular Endothelial Growth Factor (VEGF)-Mediated Diabetic Wound Healing in Streptozotocin-Induced Hyperglycemic Rats. Medical science monitor international medical journal of experimental and clinical research. 2017; 23: $555-62$.

21. Huang KX, Tao ZM, Zhang AJ, Peng SL, Ding LS. [Studies on chemical constituents of Curcuma aromatica salisb]. Zhongguo Zhong yao za zhi $=$ Zhongguo zhongyao zazhi = China journal of Chinese materia medica. 2000; 25: $163-5$

22. Wang J, Li XM, Bai Z, Chi BX, Wei Y, Chen X. Curcumol induces cell cycle arrest in colon cancer cells via reactive oxygen species and Akt/ GSK3beta/cyclin D1 pathway. Journal of ethnopharmacology. 2018; 210: 1-9.

23. Shi H, Tan B, Ji G, Lu L, Cao A, Shi S, et al. Zedoary oil (Ezhu You) inhibits proliferation of AGS cells. Chinese medicine. 2013; 8: 13.

24. Yu C, Sun X, Niu Y. An investigation of the developmental neurotoxic potential of curcumol in PC12 cells. Toxicology mechanisms and methods. 2016; 26 : 635-43.

25. Hsin MC, Hsieh YH, Wang PH, Ko JL, Hsin IL, Yang SF. Hispolon suppresses metastasis via autophagic degradation of cathepsin $\mathrm{S}$ in cervical cancer cells. Cell death \& disease. 2017; 8: e3089.

26. Gan YX, Luo NN, Jiang YP, Liu Q, Fu S, Wang L, et al. [Simultaneous determination of beta-elemene, curcumol, germacrone and neocurdione in volatile oil of Curcuma phaeocaulis and vinegar products by GC-MS]. Zhongguo Zhong yao za $\mathrm{zhi}=$ Zhongguo zhongyao zazhi $=$ China journal of Chinese materia medica. 2015; 40: 1311-5.

27. Chen G, Wang Y, Li M, Xu T, Wang X, Hong B, et al. Curcumol induces HSC-T6 cell death through suppression of Bcl-2: involvement of PI3K and NF-kappaB pathways. European journal of pharmaceutical sciences : official journal of the European Federation for Pharmaceutical Sciences. 2014; 65: 21-8.

28. Wang J, Wu J, Li X, Liu H, Qin J, Bai Z, et al. Identification and validation nucleolin as a target of curcumol in nasopharyngeal carcinoma cells. Journal of proteomics. 2018; 182: 1-11

29. Peng Z, Zhou W, Zhang C, Liu H, Zhang Y. Curcumol Controls Choriocarcinoma Stem-Like Cells Self-Renewal via Repression of DNA Methyltransferase (DNMT)- and Histone Deacetylase (HDAC)-Mediated Epigenetic Regulation. Medical science monitor : international medical journal of experimental and clinical research. 2018; 24: 461-72.

30. Wang $H$, Fang $Y$, Wang $Y$, Wang Z, Zou Q, Shi Y, et al. Inhibitory Effect of Curcumol on Jak2-STAT Signal Pathway Molecules of Fibroblast-Like Synoviocytes in Patients with Rheumatoid Arthritis. Evidence-based complementary and alternative medicine : eCAM. 2012; 2012: 746426

31. Jiang Y, Li ZS, Jiang FS, Deng X, Yao CS, Nie G. Effects of different ingredients of zedoary on gene expression of HSC-T6 cells. World journal of gastroenterology. 2005; 11: 6780-6.

32. Tang QL, Guo JQ, Wang QY, Lin HS, Yang ZP, Peng T, et al. Curcumol induces apoptosis in SPC-A-1 human lung adenocarcinoma cells and displays anti-neoplastic effects in tumor bearing mice. Asian Pacific journal of cancer prevention : APJCP. 2015; 16: 2307-12.

33. Zhang JS, Guan J, Yang FQ, Liu HG, Cheng XJ, Li SP. Qualitative and quantitative analysis of four species of Curcuma rhizomes using twice development thin layer chromatography. Journal of pharmaceutical and biomedical analysis. 2008; 48: 1024-8.

34. Yang FQ, Li SP, Zhao J, Lao SC, Wang YT. Optimization of GC-MS conditions based on resolution and stability of analytes for simultaneous determination of nine sesquiterpenoids in three species of Curcuma rhizomes. Journal of pharmaceutical and biomedical analysis. 2007; 43: 73-82.

35. Fang J, Yang B, Ge Z, Bai X, Yan B. Single standard substance for the determination of nine volatile components in the distillate of Fructus Gardeniae and Radix Curcumae (an intermediate of Xingnaojing Injection). Journal of separation science. 2017; 40: 3946-57.

36. Yin G, Cheng X, Tao W, Dong Y, Bian Y, Zang W, et al. Comparative analysis of multiple representative components in the herb pair Astragali Radix-Curcumae Rhizoma and its single herbs by UPLC-QQQ-MS. Journal of pharmaceutical and biomedical analysis. 2018; 148: 224-9.

37. Chen C, Long L, Zhang F, Chen Q, Chen C, Yu X, et al. Antifungal activity, main active components and mechanism of Curcuma longa extract against Fusarium graminearum. PloS one. 2018; 13: e0194284.

38. Huang L, Li A, Liao G, Yang F, Yang J, Chen X, et al. Curcumol triggers apoptosis of p53 mutant triple-negative human breast cancer MDA-MB 231 cells via activation of p73 and PUMA. Oncology letters. 2017; 14: 1080-8.

39. Thánh Ky P, Leo JM, Piet AL, Nguyêñ XD. Volatile Constituents of the Essential Oil of Curcuma trichosantha Gagnep. from Vietnam. Journal of Essential Oil Research. 2011; 6: 213-4.

40. Chen LX, Zhang $\mathrm{H}$, Zhao $\mathrm{O}$, Yin SY, Zhang Z, Li TX, et al. Microbial transformation of curcumol by Aspergillus niger. Natural product communications. 2013; 8: 149-52.

41. Lou $\mathrm{Y}$, Zhang $\mathrm{H}, \mathrm{He} H$, Peng $\mathrm{K}$, Kang $\mathrm{N}$, Wei $\mathrm{X}$, et al. Isolation and identification of phase 1 metabolites of curcumol in rats. Drug metabolism and disposition: the biological fate of chemicals. 2010; 38: 2014-22.

42. Khan M, Maryam A, Zhang H, Mehmood T, Ma T. Killing cancer with platycodin D through multiple mechanisms. Journal of cellular and molecular medicine. 2016; 20: 389-402

43. Amin AR, Kucuk O, Khuri FR, Shin DM. Perspectives for cancer prevention with natural compounds. Journal of clinical oncology : official journal of the American Society of Clinical Oncology. 2009; 27: 2712-25.

44. Khan M, Maryam A, Qazi JI, Ma T. Targeting Apoptosis and Multiple Signaling Pathways with Icariside II in Cancer Cells. International journal of biological sciences. 2015; 11: 1100-12.

45. Dall'Acqua S. Natural products as antimitotic agents. Current topics in medicinal chemistry. 2014; $14: 2272-85$.

46. Pratheeshkumar P, Sreekala C, Zhang Z, Budhraja A, Ding S, Son YO, et al. Cancer prevention with promising natural products: mechanisms of action and molecular targets. Anti-cancer agents in medicinal chemistry. 2012; 12: 1159-84

47. Rahmani AH, Alzohairy MA, Khan MA, Aly SM. Therapeutic Implications of Black Seed and Its Constituent Thymoquinone in the Prevention of Cancer through Inactivation and Activation of Molecular Pathways. Evidence-based complementary and alternative medicine : eCAM. 2014; 2014: 724658.

48. Ghantous A, Sinjab A, Herceg Z, Darwiche N. Parthenolide: from plant shoots to cancer roots. Drug discovery today. 2013; 18: 894-905.

49. Li YX, Himaya SW, Kim SK. Triterpenoids of marine origin as anti-cancer agents. Molecules. 2013; 18: 7886-909.

50. Spatafora C, Tringali C. Natural-derived polyphenols as potential anticancer agents. Anti-cancer agents in medicinal chemistry. 2012; 12: 902-18.

51. Hikino H, Meguro K, Sakurai Y, Takemoto T. Structure of curcumol. Chemical \& pharmaceutical bulletin. 1966; 14: 1241-9.

52. Zhang W, Wang Z, Chen T. Curcumol induces apoptosis via caspases-independent mitochondrial pathway in human lung adenocarcinoma ASTC-a-1 cells. Medical oncology. 2011; 28: 307-14

53. Ning L, Ma H, Jiang Z, Chen L, Li L, Chen Q, et al. Curcumol Suppresses Breast Cancer Cell Metastasis by Inhibiting MMP-9 Via JNK1/2 and Akt-Dependent NF-kappaB Signaling Pathways. Integrative cancer therapies. 2016; 15: 216-25

54. Wang J, Chen X, Zeng JH. [Effect of curcumol on proliferation and apoptosis of nasopharyngeal carcinoma cell line CNE-2]. Xi bao yu fen zi mian yi xue za $\mathrm{zhi}=$ Chinese journal of cellular and molecular immunology. 2011; 27: 790-2.

55. Huang LZ, Wang J, Lu FT, Yang FC, Chen X, Hong X, et al. [Mechanism study on anti-proliferative effects of curcumol in human hepatocarcinoma HepG2 cells]. Zhongguo Zhong yao za $\mathrm{zhi}=$ Zhongguo zhongyao zazhi $=$ China journal of Chinese materia medica. 2013; 38: 1812-5

56. Wang J, Huang F, Bai Z, Chi B, Wu J, Chen X. Curcumol Inhibits Growth and Induces Apoptosis of Colorectal Cancer LoVo Cell Line via IGF-1R and p38 MAPK Pathway. International journal of molecular sciences. 2015; 16: 19851-67.

57. Han $\mathrm{F}$, Wang $\mathrm{L}$, Cong $\mathrm{J}, \mathrm{Fu} \mathrm{Y}, \mathrm{Wu} \mathrm{X}$. The effect of curcumol on protein expression of JAK2/STAT3 signaling pathway in human ovarian cancer line SKOV3. Global Journal of Integrated Chinese Medicine and Western Medicine. 2013; 1.

58. Asghar U, Witkiewicz AK, Turner NC, Knudsen ES. The history and future of targeting cyclin-dependent kinases in cancer therapy. Nature reviews Drug discovery. 2015; 14: 130-46. 
59. Nagle A, Hur W, Gray NS. Antimitotic agents of natural origin. Current drug targets. 2006; 7: 305-26.

60. Ranjan A, Fofaria NM, Kim SH, Srivastava SK. Modulation of signal transduction pathways by natural compounds in cancer. Chinese journal of natural medicines. 2015; 13: 730-42.

61. Bailon-Moscoso N, Cevallos-Solorzano G, Romero-Benavides JC, Orellana MI. Natural Compounds as Modulators of Cell Cycle Arrest: Application for Anticancer Chemotherapies. Current genomics. 2017; 18: 106-31.

62. Grant S, Roberts JD. The use of cyclin-dependent kinase inhibitors alone or in combination with established cytotoxic drugs in cancer chemotherapy. Drug resistance updates : reviews and commentaries in antimicrobial and anticancer chemotherapy. 2003; 6: 15-26.

63. Li X, Liu H, Wang J, Qin J, Bai Z, Chi B, et al. Curcumol induces cell cycle arrest and apoptosis by inhibiting IGF-1R/PI3K/Akt signaling pathway in human nasopharyngeal carcinoma CNE-2 cells. Phytotherapy research : PTR. 2018; 32: 2214-25.

64. Cai F, Chen M, Zha D, Zhang P, Zhang X, Cao N, et al. Curcumol potentiates celecoxib-induced growth inhibition and apoptosis in human non-small cell lung cancer. Oncotarget. 2017; 8: 115526-45.

65. Jing Z, Xie CY, Wu ZQ, Xu F, Zou CL. [Effects end mechanisms of curcumol beta-cyclodextrin compound on the proliferation and apoptosls of esophageal carcinoma cell line TE-1]. Zhongguo Zhong xi yi jie he za zhi Zhongguo Zhongxiyi jiehe zazhi $=$ Chinese journal of integrated traditional and Western medicine. 2013; 33: 85-9.

66. Yan D, Deng S, Gan W, Li S, Li Y. Curcumol attenuates epithelial-mesenchymal transition of nasopharyngeal carcinoma cells via TGF-beta1. Molecular medicine reports. 2018; 17: 7513-20.

67. Qi H, Ning L, Yu Z, Dou G, Li L. Proteomic Identification of eEF1A1 as a Molecular Target of Curcumol for Suppressing Metastasis of MDA-MB-231 Cells. Journal of agricultural and food chemistry. 2017.

68. Zang S, Tang O, Dong F, Liu H, Li L, Guo F, et al. Curcumol inhibits the proliferation of gastric adenocarcinoma MGC-803 cells via downregulation of IDH1. Oncology reports. 2017; 38: 3583-91.

69. Liu H, Wang J, Tao Y, Li X, Qin J, Bai Z, et al. Curcumol inhibits colorectal cancer proliferation by targeting miR-21 and modulated PTEN/PI3K/Akt pathways. Life sciences. 2019; 221: 354-61.

70. Zhang C, Wang LM. Inhibition of autophagy attenuated curcumol-induced apoptosis in MG-63 human osteosarcoma cells via Janus kinase signaling pathway. Oncology letters. 2017; 14: 6387-94.

71. Zhou L, Wei E, Zhou B, Bi G, Gao L, Zhang T, et al. Anti-proliferative benefit of curcumol on human bladder cancer cells via inactivating EZH2 effector. Biomedicine \& pharmacotherapy = Biomedecine \& pharmacotherapie. 2018; 104: 798-805.

72. Rasul A, Khan M, Ali M, Li J, Li X. Targeting apoptosis pathways in cancer with alantolactone and isoalantolactone. TheScientificWorldJournal. 2013; 2013: 248532.

73. Elmore S. Apoptosis: a review of programmed cell death. Toxicologic pathology. 2007; 35: 495-516.

74. Evan GI, Vousden KH. Proliferation, cell cycle and apoptosis in cancer. Nature. 2001; 411: 342-8.

75. Castro RE, Santos MM, Gloria PM, Ribeiro CJ, Ferreira DM, Xavier JM, et al. Cell death targets and potential modulators in Alzheimer's disease. Current pharmaceutical design. 2010; 16: 2851-64.

76. Ravishankar B, Liu H, Shinde R, Chaudhary K, Xiao W, Bradley J, et al. The amino acid sensor GCN2 inhibits inflammatory responses to apoptotic cells promoting tolerance and suppressing systemic autoimmunity. Proceedings of the National Academy of Sciences of the United States of America. 2015; 112: 10774-9.

77. Ashkenazi A. Targeting the extrinsic apoptotic pathway in cancer: lessons learned and future directions. The Journal of clinical investigation. 2015; 125: 487-9.

78. Rasul A, Millimouno FM, Ali Eltayb W, Ali M, Li J, Li X. Pinocembrin: a novel natural compound with versatile pharmacological and biological activities. BioMed research international. 2013; 2013: 379850.

79. Rasul A, Khan $\mathrm{M}, \mathrm{Yu}_{\mathrm{u}} \mathrm{B}$, Ali M, Bo YJ, Yang $\mathrm{H}$, et al. Isoalantolactone, a sesquiterpene lactone, induces apoptosis in SGC-7901 cells via mitochondrial and phosphatidylinositol 3-kinase/Akt signaling pathways. Archives of pharmacal research. 2013; 36: 1262-9.

80. Rasul A, Zhao BJ, Liu J, Liu B, Sun JX, Li J, et al. Molecular mechanisms of casticin action: an update on its antitumor functions. Asian Pacific journal of cancer prevention : APJCP. 2014; 15: 9049-58.

81. Rasul A, Yu B, Khan M, Zhang K, Iqbal F, Ma T, et al. Magnolol, a natural compound, induces apoptosis of SGC-7901 human gastric adenocarcinoma cells via the mitochondrial and PI3K/Akt signaling pathways. International journal of oncology. 2012; 40: 1153-61.

82. Rasul A, Bao R, Malhi M, Zhao B, Tsuji I, Li J, et al. Induction of apoptosis by costunolide in bladder cancer cells is mediated through ROS generation and mitochondrial dysfunction. Molecules. 2013; 18: 1418-33.

83. Rasul A, Di J, Millimouno FM, Malhi M, Tsuji I, Ali M, et al. Reactive oxygen species mediate isoalantolactone-induced apoptosis in human prostate cancer cells. Molecules. 2013; 18: 9382-96.

84. Zafar M, Sarfraz I, Rasul A, Jabeen F, Samiullah K, Hussain G, et al. Tubeimoside-1, Triterpenoid Saponin, as a Potential Natural Cancer Killer Natural product communications. 2018; 13: 643-50.
85. Wu JT, Kral JG. The NF-kappaB/IkappaB signaling system: a molecular target in breast cancer therapy. The Journal of surgical research. 2005; 123: 158-69.

86. Lee $\mathrm{CH}$, Jeon YT, Kim SH, Song YS. NF-kappaB as a potential molecular target for cancer therapy. BioFactors. 2007; 29: 19-35.

87. Lou C, Takahashi K, Irimura T, Saiki I, Hayakawa Y. Identification of Hirsutine as an anti-metastatic phytochemical by targeting NF-kappaB activation. International journal of oncology. 2014; 45: 2085-91.

88. Santarpia L, Lippman SM, El-Naggar AK. Targeting the MAPK-RAS-RAF signaling pathway in cancer therapy. Expert opinion on therapeutic targets. 2012; 16: 103-19.

89. Son Y, Kim S, Chung HT, Pae HO. Reactive oxygen species in the activation of MAP kinases. Methods in enzymology. 2013; 528: 27-48.

90. Faes S, Dormond O. PI3K and AKT: Unfaithful Partners in Cancer. International journal of molecular sciences. 2015; 16: 21138-52

91. Guo P, Wang YW, Weng BX, Li XK, Yang SL, Ye FQ. Synthesis, anti-tumor activity, and structure-activity relationships of curcumol derivatives. Journal of Asian natural products research. 2014; 16: 53-8.

92. Liu YM, Fan HR, Ding J, Huang C, Deng S, Zhu T, et al. Curcumol allosterically modulates $\mathrm{GABA}(\mathrm{A})$ receptors in a manner distinct from benzodiazepines. Scientific reports. 2017; 7: 46654. 